\title{
Analisis Sentimen Sosial Media Twitter Dengan Algoritma Machine Learning Menggunakan Software $\mathbf{R}$
}

\author{
Jaka Aulia Pratama1, Yadi Suprijadi², dan Zulhanif ${ }^{2}$ \\ ${ }^{1}$ Magister Statistika Terapan; ${ }^{2}$ Departemen Statistika, Universitas Padjadjaran, Bandung, Jl. Raya \\ Bandung Sumedang KM.21, Hegarmanah, Jatinangor, Kabupaten Sumedang, Jawa Barat 45363, \\ Indonesia
}

Korespondensi; Jaka Aulia Pratama, Email: jakajek@gmail.com

\begin{abstract}
Abstrak
Media sosial adalah wadah untuk mengungkapkan opini terhadap suatu topik tertentu. Ketersediaan informasi dan opini dari para pengguna media sosial merupakan kumpulan dokumen data berupa teks yang amat sangat besar dan berguna untuk kepentingan penelitian maupun membuat suatu keputusan bagi pihak - pihak tertentu. Text Mining bisa didefinisikan sebagai proses penggalian informasi di mana pengguna berinteraksi dengan kumpulan dokumen dari waktu ke waktu dengan menggunakan suatu alat analisis. Analisis sentimen atau Opinion Mining adalah salah satu studi di bidang komputasi yang berhubungan dengan kasus publik mengenai opini, penilaian, sikap, dan emosi. Penelitian ini akan menggunakan metode Machine Learning pada analisis sentimen pengguna layanan jejaring sosial Twitter terhadap Donald Trump dan Barack Obama dalam 20000 tweets. Nilai akurasi metode Machine Learning yang diperoleh cukup tinggi yaitu $87.52 \%$ untuk Data Training dan $87.4 \%$ untuk Data Testing.
\end{abstract}

Kata Kunci: Analisis Sentimen; Text Mining; Machine Learning; R

\begin{abstract}
Social media is a place to express opinions on a particular topic. The availability of information and opinions from social media users is a collection of data documents in the form of very large textual data and its useful for the research purposes and make a decision for certain parties. Text Mining can be defined as a process of extracting information in which the user interacts with the documents over time using an analysis tool. Opinion Mining analysis is one of computational studies related to public case concerning opinion, judgment, attitude, and emotion. This study will use the method of Machine Learning algorithm on the analysis of Twitter user sentiment toward Donald Trump and Barack Obama in 20000 tweets. The accuracy of Machine Learning method obtained is high enough that is $87.52 \%$ for Data Training and $87.4 \%$ for Data Testing.
\end{abstract}

Keywords: Sentiment Aanalysis; Text Mining; Machine Learning; R

\section{Pendahuluan}

Media sosial merupakan salah satu fitur berbasis teknologi dalam CMC (Computer-Mediated Communication) yang mampu memfasilitasi komunikasi antar manusia melalui perangkat elektronik. Menurut Steve (2015) dan Nicole B. (2007) media sosial memudahkan pengembangan jejaring sosial online dengan menghubungkan profil pengguna dengan profil orang lain atau kelompok lainnya. Sejarah media sosial dimulai saat peneliti di ARPA (Advanced Research Projects Agency) mengirimkan email pertama kali di dunia pada tahun 1971, tapi perkembangan media sosial tidak begitu baik pada masa itu hingga Tim-Berners Lee memulai revolusi internet melalui penemuan World Wide Web (WWW) di tahun 1991. Revolusi internet membuka jalan baru bagi para pencipta dan pengembang layanan jaringan sosial online. Hingga tahun 2017 platform layanan jejaring sosial yang paling populer di dunia adalah Twitter, Facebook, Instagram dan Snapchat.

Twitter adalah layanan jejaring sosial dan portal berita online dimana penggunannya saling berinteraksi melalui pesan berbasis teks dengan batas maksimum seratus empat puluh karakter dalam satu tweet. Didalam Twitter terdapat istilah trending topics yaitu dimana kata, frasa, dan topik yang 
spesifik di tweet oleh banyak pengguna dalam satu waktu. Selain itu Twitter juga identik dengan konsep penggunaan hash tag dimana pengguna dapat menggunakan symbol hash tag \# sebelum kata kunci atau frasa yang relevan pada tweet untuk mengkategorikan tweet nya juga membantunya agar lebih mudah muncul di laman pencarian tweet dan mempermudah untuk ikut berpastisipasi pada trending topics. Penggunaan hash tag relatif mempermudah pengklasifikasian teks karena hash tag dapat menunjukan emosi atau opini pengguna twitter. Sebagai contoh, \#MakeAmericaGreatAgain adalah Hash Tag resmi untuk Kandidat Presiden Partai Republik Donald Trump. Semua tweet yang terdiri dari hash tag tersebut mengindikasikan dukungan kepada Donald Trump (Ramteke, 2016).

Dalam dunia Data Mining kita dituntut untuk mampu menggali segala macam informasi pada sumber data apapun, salah satunya adalah data berupa teks. Text Mining bisa didefinisikan sebagai proses penggalian informasi di mana pengguna berinteraksi dengan kumpulan dokumen dari waktu ke waktu dengan menggunakan suatu alat analisis. Text Mining mencari informasi berarti dari sumbersumber data melalui identifikasi dan eksplorasi pola tertentu, dalam kasus ini sumber data adalah kumpulan dokumen dengan pola yang ditemukan pada data teks yang tidak berstruktur. Oleh karenanya Twitter dapat dijadikan salah satu sumber data berupa teks untuk penelitian Text Mining.

Penelitian ini bertujuan untuk menerapkan analisis sentiment dan Text Mining pada layanan jejaring sosial Twitter menggunakan algoritma Machine Learning dengan contoh kasus sentimen pengguna Twitter berbahasa inggris kepada Donald Trump dan Barack Obama selama bulan Agustus 2017 hingga September 2017 dengan menggunakan software $R$.

\section{Landasan Teori}

\section{Text Mining}

Text Mining bisa didefinisikan sebagai proses penggalian informasi di mana pengguna berinteraksi dengan kumpulan dokumen dari waktu ke waktu dengan menggunakan suatu alat analisis. Text Mining mencari informasi berarti dari sumber-sumber data melalui identifikasi dan eksplorasi pola tertentu, dalam kasus ini sumber data adalah kumpulan dokumen dengan pola yang ditemukan pada data teks yang tidak berstruktur. Praproses dari Text Mining sendiri berpusat pada identifikasi dan ekstraksi fitur representatif untuk dokumen Natural Language. (Feldman \& Sanger 2007).

Proses Text Mining biasanya membutuhkan penyusunan teks masukan berdasarkan tata bahasa, yang diikuti dengan menggali pola dari data yang sudah terstruktur, evaluasi dan interpretasi hasil. Proses ini biasanya digunakan untuk pengklasifikasian, penggerombolan, analisis makna, pengambil kesimpulan dari dokumen dan pemodelan hubungan objek yang berupa kata (Han \& Kamber 2001).

\section{Analisis Sentimen}

Analisis sentimen atau Opinion Mining adalah salah satu studi di bidang komputasi yang berhubungan dengan kasus publik mengenai opini, penilaian, sikap, dan emosi. Opini bersifat subjektif, dan tidak cukup apabila diperoleh hanya dari satu orang untuk membangun suatu ringkasan opini. Secara umum opini terbagi menjadi dua yaitu Regular Opinions dan Comparative Opinions. Regular Opinions adalah sentimen atau opini berupa ekspresi pada suatu entitas atau sesuatu yang berwujud. Sedangkan Comparative Opinions adalah perbandingan lebih dari satu entitas. Regular Opinions terbagi menjadi dua jenis yaitu Direct Opinions dan Indirect Opinions (Jindal \& Liu, 2010).

Menurut Liu (2012), opini terdiri dari Lima bagian yaitu entitas, aspek, sentimen, Holder dan waktu. Dimana,

1. Entitas : Target entitas atau objek

2. Aspek : Aspek atau fitur pada entitas

3. Sentimen : Positif, negatif, netral, sebuah rating, atau suatu emosi

4. Holder : Pemilik opini

5. Waktu : Waktu ketika opini disampaikan.

Kalimat subjektif menyampaikan perasaan pribadi, sudut pandang, emosi atau keyakinan. Sedangkan kalimat objektif merepresentasikan informasi faktual. Kebanyakan opini merupakan kalimat subjektif, namun kalimat objektif dapat mengartikan opini juga (Liu, 2010). Dengan banyaknya opini maka kita 
memerlukan suatu ringkasan. Ringkasan tersebut harus berupa kuantitatif dan dapat didefinisikan secara akurat (Hu \& Liu, 2004).

Sentiment Classification adalah solusi dari Un-Supervised Text Classification. Sentiment Classification pada tahap dokumen atau kalimat kurang mampu mengidentifikasi tujuan dari opini (Liu, 2014). Oleh karena itu diperlukan ekstraksi aspek-aspek dan suatu Corpus opini dengan pendekatan sebagai berikut:

1. Mencari Frequent Nouns dan frase Noun

2. Pemanfaatan opini dan kaitannya dengan target

3. Supervised Learning

4. Topic Modelling

\section{Algoritma Machine Learning}

Machine Learning adalah salah satu disiplin ilmu dari Computer Science yang mempelajari bagaimana membuat komputer/mesin itu mempunyai suatu kecerdasan mempunyai suatu kecerdasan. Agar mempunyai suatu kecerdasan, komputer/mesin harus dapat belajar. Dengan kata lain, Machine Learning adalah suatu bidang keilmuan yang berisi tentang pembelajaran komputer/mesin untuk menjadi cerdas. Salah satu metode dalam Machine Learning adalah Concept Learning, metode ini membutuhkan Data Training dan mampu mengatasi data negative maupun positif karena termasuk ke dalam Supervised Learning (Mitchell \& Hill, 2008).

Supervised Learning adalah teknik dengan membuat suatu fungsi dari data latihan yang terdiri dari pasangan nilai input (dalam bentuk vector), dan output yang diharapkan untuk input yang bersangkutan. Tugas dari mesin Supervised Learning adalah memprediksi nilai fungsi untuk semua nilai input yang mungkin, setelah mengalami sejumlah data latihan. Untuk mencapai tujuan ini mesin harus dapat melakukan proses generalisasi dari data latihan yang diberikan, untuk memprediksikan nilai output dari input yang belum pernah diberikan sebelumnya dengan cara yang masuk akal (Andoko, 2007).

\section{Bahan dan Metode}

Data teks yang digunakan pada penelitian ini diambil dari layanan jejaring sosial Twitter sebanyak 10000 tweets kepada \#Trump OR @DonaldTrump dan 10000 tweets kepada \#Obama OR @BarackObama dari tanggal 1 Agustus 2017 sampai dengan tanggal 27 September 2017.

Tabel 1 Data Training Sergey Bryl.

\begin{tabular}{|c|c|c|c|c|}
\hline No. & Sentiment & Time & Username & Tweets \\
\hline 1 & 0 & $\begin{array}{l}\text { Mon Apr } 06 \\
\text { 22:19:45 } \\
\text { PDT } 2009\end{array}$ & _TheSpecialOne_ & $\begin{array}{l}\text { http://twitpic.com/2y1zl - You shoulda got David } \\
\text { Carr of Third Day to do it. ;D }\end{array}$ \\
\hline 2 & 0 & $\begin{array}{l}\text { Mon Apr } 06 \\
\text { 22:19:49 } \\
\text { PDT } 2009\end{array}$ & scotthamilton & $\begin{array}{l}\text { is upset that he can't update his Facebook by } \\
\text { texting it... and might cry as a result School } \\
\text { today also. Blah! }\end{array}$ \\
\hline 3 & 0 & $\begin{array}{l}\text { Mon Apr } 06 \\
\text { 22:19:53 } \\
\text { PDT } 2009\end{array}$ & mattycus & $\begin{array}{l}\text { @Kenichan I dived many times for the ball. } \\
\text { Managed to save } 50 \% \text { The rest go out of } \\
\text { bounds }\end{array}$ \\
\hline$\vdots$ & & $\vdots$ & $\vdots$ & $\vdots$ \\
\hline 1599999 & 4 & $\begin{array}{l}\text { Fri May } 29 \\
07: 33: 44 \\
\text { PDT } 2009\end{array}$ & jonasobsessedx & @DestinyHope92 im great thaanks wbuu? \\
\hline 1600000 & 4 & $\begin{array}{l}\text { Fri May } 29 \\
07: 33: 45 \\
\text { PDT } 2009\end{array}$ & sugababez & cant wait til her date this weekend \\
\hline
\end{tabular}


Data Training pada penelitian ini diperoleh dari penelitian sebelumnya yang dilakukan oleh Sergey Bryl pada bulan Agustus 2017. Data Training terdiri dari 1.600 .000 tweets berbahasa inggris yang dikumpulkan secara acak dengan masing masing tweet memiliki nilai 0 (negative) sampai dengan 4 (positif) dimana nilai tersebut adalah polaritas kandungan kata negatif dan positif dalam sebuah tweet. Tabel 1 adalah tabel yang memperlihatkan Data Training yang dilakukan pada penelitian ini.

Sebelum digunakan dalam penelitian ini, Data Training harus melalui beberapa proses selanjutnya seperti Cleaning Data, Splitting Data, Preprocessing Data, Tokenization, Vectorization dan Train Model. Pada tahapan Train Model digunakan metode Cross-Validation Generalized Linear Model dengan folds sebanyak lima kali, iterasi sebanyak seribu dan batas konvergen pada 0.001. Nilai AUC (Area Under Curve) yang diperoleh pada tahapan Train Model adalah 0.8752 untuk Data Training dan 0.8740 untuk Data Testing. Hasil tersebut menunjukan bahwa model memiliki nilai akurasi yang tinggi yaitu 87.5\% untuk Data Training dan $87.4 \%$ untuk Data Testing. Model tersebut disimpan sebagai suatu fungsi pada software $R$ yang selanjutnya akan digunakan untuk data teks 10000 tweets kepada "\#Trump OR@DonaldTrump" dan 10000 tweets kepada \#Obama OR @BarackObama dari tanggal 1 Agustus 2017 sampai dengan tanggal 27 September 2017.

Berikut adalah daftar package pada software $R$ yang digunakan dalam penelitian ini:

Tabel 2 Daftar package R.

\begin{tabular}{lllllllll}
\hline No & 1 & 2 & 3 & 4 & 5 & 6 & 7 & 8 \\
\hline Package & twitteR & ROAuth & tidyverse & purrrlyr & text2vec & caret & glmnet & ggrepel \\
\hline
\end{tabular}

\section{Hasil dan Pembahasan}

Berikut adalah hasil analisis sentiment pengguna layanan jejaring sosial Twitter dalam 10000 tweets kepada "\#Trump OR @DonaldTrump" dari tanggal 1 Agustus 2017 sampai dengan tanggal 27 September 2017.

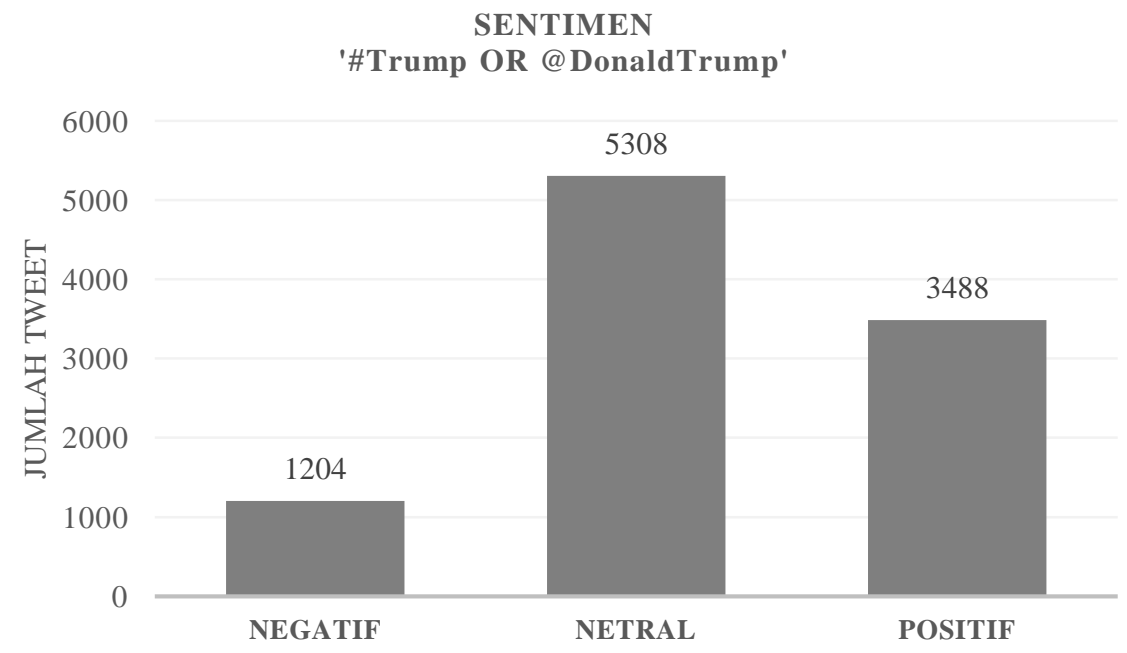

Gambar 1 Hasil Analisis Sentimen "\#Trump OR @DonaldTrump".

Terlihat pada Gambar 1 bahwa sentiment pengguna layanan jejaring sosial Twitter terhadap "\#Trump OR @DonaldTrump" dari tanggal 1 Agustus 2017 sampai dengan tanggal 27 September 2017 pada 10000 tweets didominasi oleh sentiment netral dengan sebanyak 5308 tweets. Sedangkan untuk tweets dengan sentiment negative diperoleh sebanyak 1204 tweets dan tweets dengan sentiment positif diperoleh sebanyak 3488 tweets.

Berikut adalah hasil analisis sentiment pengguna layanan jejaring sosial Twitter dalam 10000 tweets kepada "\#Obama OR @BarackObama" dari tanggal 1 Agustus 2017 sampai dengan tanggal 27 September 2017. 


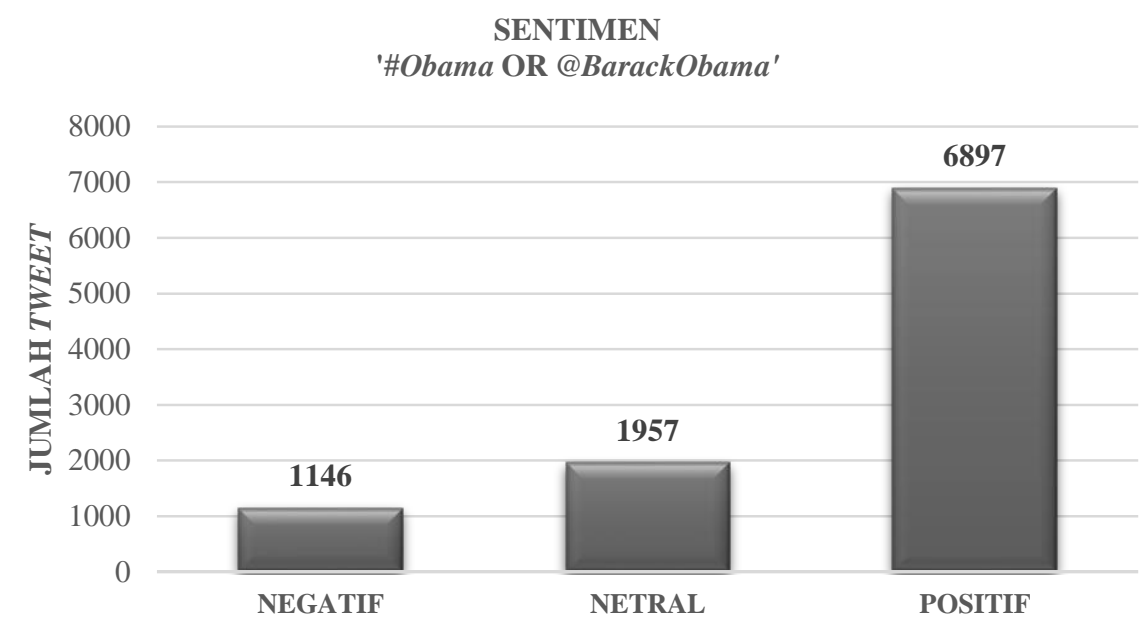

Gambar 2 Hasil Analisis Sentimen "\#Obama OR @BarackObama".

Terlihat pada Gambar 2 bahwa sentiment pengguna layanan jejaring sosial Twitter terhadap "\#Obama OR@BarackObama" dari tanggal 1 Agustus 2017 sampai dengan tanggal 27 September 2017 pada 10000 tweets didominasi oleh sentiment positif dengan sebanyak 6897 tweets. Sedangkan untuk tweets dengan sentiment negative diperoleh sebanyak 1146 tweets dan tweets dengan sentiment netral diperoleh sebanyak 1957 tweets.

\section{Kesimpulan}

Besarnya jumlah dalam Data Training dan tingginya nilai akurasi dalam penelitian ini menunjukan bahwa analisis sentimen Twitter menggunakan algoritma Machine Learning merupakan salah satu alternatif yang bagus dalam penelitian Text Mining. Hanya saja metode Machine Learning membutuhkan perangkat keras dengan spesifikasi cukup tinggi dalam proses pengerjaanya. Kendala penelitian ini terdapat pada akses data Twitter yang terbatas oleh waktu. Waktu maksimal data tweets yang bisa diakses adalah dua bulan kebelakang jika menggunakan software $R$.

Waktu yang dibutuhkan selama proses Cleaning Data, Splitting Data, Preprocessing Data, Tokenization, Vectorization dan Train Model adalah 88.53525 menit. Penelitian ini menggunakan software R, jaringan internet dengan kecepatan 12.7 mbps, komputer dengan spesifikasi Intel Core i5 $7200 U$ dan RAM 8 GB.

\section{Referensi}

[1] Andoko. 2007. Perancangan Program Simulasi Deteksi Wajah Dengan Support Vector Machines - Viola Jones. Skripsi Teknik Informatika dan Matematika Universitas Bina Nusantara, Jakarta.

[2] Feldman, R., Sanger, J. 2007. The text mining handbook: advanced approaches in analyzing unstructured data. Cambridge University Press.

[3] J. Han,. M. Kamber. 2001. Data Mining Concepts and Techniques. Morgan Kaufmann, San Francisco

[4] J. Ramteke., S. Shah., D. Godhia., A. Shaikh. 2016. Election result prediction using Twitter sentiment analysis. International Conference on Inventive Computation Technologies (ICICT), Coimbatore, 2016, pp. 1-5.

[5] Liu, B. 2012. Sentiment Analysis and Opinion Mining. Morgan and Claypool publishers. 